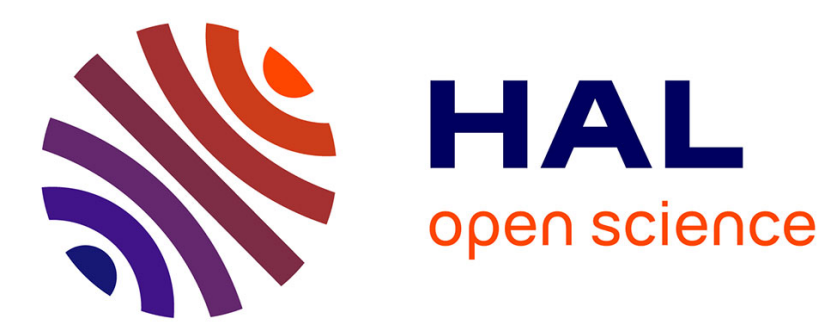

\title{
Size dependence of the percolation threshold of square and triangular network
}

J. Roussenq, J. Clerc, G. Giraud, E. Guyon, H. Ottavi

\section{To cite this version:}

J. Roussenq, J. Clerc, G. Giraud, E. Guyon, H. Ottavi. Size dependence of the percolation threshold of square and triangular network. Journal de Physique Lettres, 1976, 37 (5), pp.99-101. 10.1051/jphyslet:0197600370509900 . jpa-00231255

\section{HAL Id: jpa-00231255 https://hal.science/jpa-00231255}

Submitted on 1 Jan 1976

HAL is a multi-disciplinary open access archive for the deposit and dissemination of scientific research documents, whether they are published or not. The documents may come from teaching and research institutions in France or abroad, or from public or private research centers.
L'archive ouverte pluridisciplinaire HAL, est destinée au dépôt et à la diffusion de documents scientifiques de niveau recherche, publiés ou non, émanant des établissements d'enseignement et de recherche français ou étrangers, des laboratoires publics ou privés. 


\title{
SIZE DEPENDENCE OF THE PERCOLATION THRESHOLD OF SQUARE AND TRIANGULAR NETWORK (*)
}

\author{
J. ROUSSENQ, J. CLERC, G. GIRAUD, E. GUYON and H. OTTAVI $\left({ }^{* *}\right)$
}

Groupe de Physique de l'Université de Provence, Centre Saint-Jérôme, 13397 Marseille Cédex 4, France

(Reçu le 26 février 1976, accepté le 15 mars 1976)

\begin{abstract}
Résumé. - On étudie au moyen d'une simulation par ordinateur l'influence de la taille du réseau sur l'apparition du seuil de percolation pour des réseaux plans limités carrés et triangulaires.

Cette étude permet d'apprécier la taille minimale compatible avec une précision fixée pour la détermination du seuil.

L'hypothèse d'universalité fournit un moyen d'exprimer cet effet de taille en fonction d'une longueur de corrélation unique.

Abstract. - We study the size dependence of the percolation threshold of square and triangular networks by a computation simulation method.

This work gives an estimate of the accuracy on the threshold determination, which can be reached as a function of the size of the network.

This size effect can be explained using a single correlation length in accordance with the universality hypothesis.
\end{abstract}

Recently a number of studies based on computational (Monte-Carlo) [1] methods, or analog models $[2,3]$ have provided data on the percolation threshold $p_{\mathrm{c}}$ and onset of conduction above $p_{\mathrm{c}}$ in various 2 or 3 dimensional networks. We have obtained a description of the conduction problem for 3D percolation in a disordered mixture of conducting and insulating, but otherwise similar, spheroids [4]. In these studies, because of the finite number $N$ of elements, transitions around $p_{\mathrm{c}}$ are smeared.

It is the purpose of this letter to discuss in more detail the size effect involved in site percolation. The study is based on a computer simulation on 2D square and triangular lattices. The size of the regular network is characterized by the number $n(20 \leqslant n \leqslant 1000)$ such that the total number of elements is $N=n^{2}$. Each site has a probability $p$ to be conducting obtained in a random way from a pseudo-random number generating subprogram. The program gives the number of clusters of conducting sites, their extent along two orthogonal directions and the number of sites in each cluster. If a cluster contains elements in both the first and last row the

$\left(^{*}\right)$ Work partly supported by the D.G.R.S.T., contract $n^{\circ} 736$ PE.

$\left({ }^{* *}\right)$ Laboratoire d'électronique de l'Université de Provence, Centre de St-Jérôme, 13397 Marseille-Cedex 4, France. corresponding configuration is said to be conducting [5].

For given size $N$ and doping $p, m$ configurations are drawn, $l$ of which are conducting. The ratio $l / m$ gives an estimate of the probability of conduction $\Pi$. For small networks : $n=20$ we have produced $m=100$ configurations. Because of the increase of computational time, $m$ was limited to 25 for $n=100$ and to 5 for $n=1000$. (For this experiment the solution of a network requires 30 minutes on a PDP 11 computer). For the same reason we have limited $n$ to 300 for triangular networks.

Figure 1 gives $\Pi(p)$ in square networks for different values of $n$. Let us consider one curve, say $n=20$. For $p$ smaller than 0.45 we find no conducting configuration whereas, for $p$ larger than 0.70 , all configurations are conducting. We characterize the limit of the transition regime by the values $p_{1}=0.52$ and $p_{2}=0.65$ such that $\Pi=0.1$ and $\Pi=0.9$. The transition region becomes narrower as $n$ increases. The same features can be observed on all the curves plotted for square and triangular lattices.

In figure 2, we have plotted $n$ versus $p_{1}$ and $p_{2}$ on a semilog scale. The curve indicates a divergence for infinite networks around the critical value $p_{\mathrm{c}}$. Note the rather symmetrical shape of the curves around $p_{\mathrm{c}}$. From the largest network data it is possible 


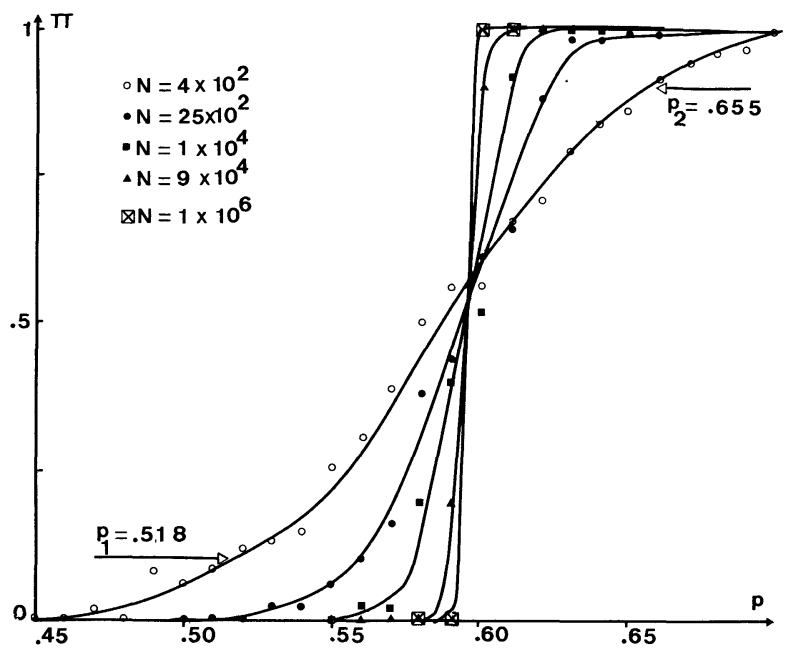

FIG. 1. - Gives the probability of conduction across a square network of $n$ elements versus the probability of site conduction.

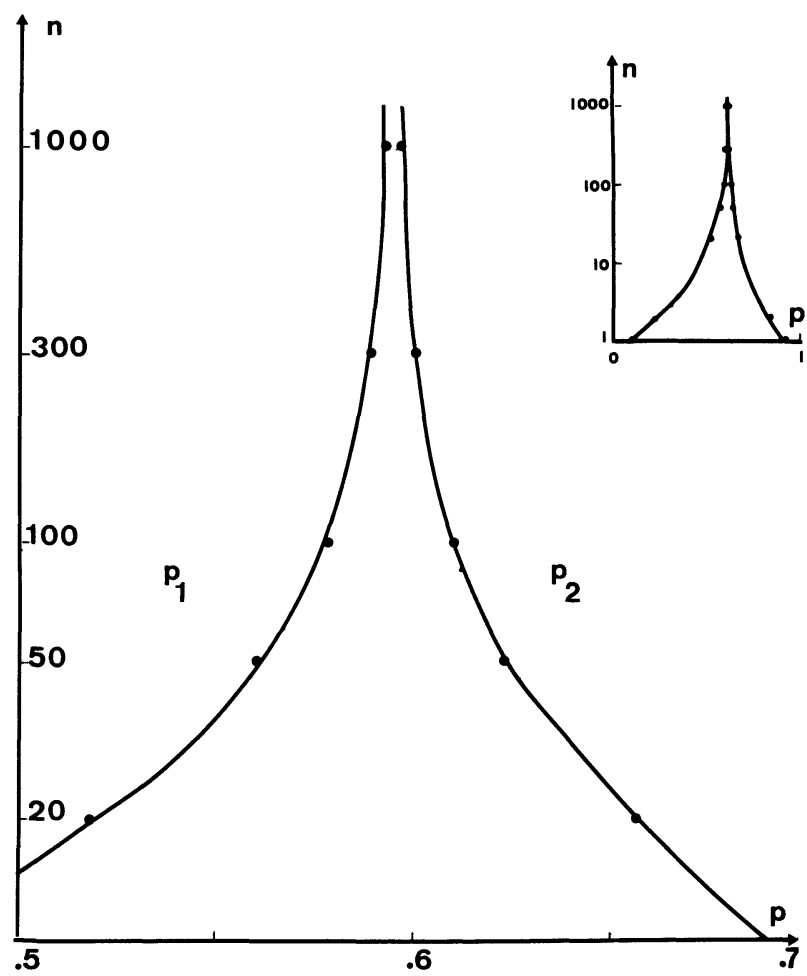

FIG. 2. $-p_{1}$ and $p_{2}$ are defined on figure 1 for $n=20$. The inse gives the complete curve from $n=1$ to 1000 for a square network. The values for small $N$ have been computed numerically (for $n=1$, $p_{1}=0.1$ and $p_{2}=0.9$; for $n=2, p_{1}=0.23, p_{2}=0.83$ ).

to obtain an estimate of the percolation threshold from the inequality $p_{1}<p_{\mathrm{c}}<p_{2}$ with an absolute accuracy better than $10^{-2}$. These results are in good agreement with the exact value for the triangular lattice $\left(p_{\mathrm{c}}=\frac{1}{2}\right)$ and with independent determinations of the percolation threshold for site problem in a square lattice $[1,6], p_{\mathrm{c}}=0.59 \pm 0.01$.

In the description of the static critical behaviour around a second order phase transition, one expects size effects to scale in terms of a single correlation length, here $\xi(p)[6]$, which should diverge at the critical threshold. We can understand our results qualitatively in terms of a cluster description of a phase transition. If one assumes that this is the case in the percolation problem, the $n(p)$ variation of figure 2 displays the expected divergence of the correlation length around $p_{\mathrm{c}}$. More qualitatively one sees that the value $p_{1}(n)<p_{\mathrm{c}}$ (pretransitional behaviour) corresponds to the growth of conducting clusters up to the size $n$. The value $p_{2}(n)>p_{\mathrm{c}}$ (limit of the critical regime in a finite geometry) can be analyzed in a similar fashion if one considers the matching lattice. For $p>p_{2}$, the non conducting clusters are too small to prevent the formation of conducting channels through the limited geometry. We therefore consider the possibility of a critical dependence.

$$
n\left(p_{i}\right) \propto \xi\left(p_{i}\right)=A / p_{i}-\left.p_{\mathrm{c}}\right|^{-v} \quad i=1,2 .
$$

In figure 3 we have tested this dependence using a $\log -\log$ plot. For triangular lattice, where $p_{c}=1 / 2$ is known exactly (a fortunate but rare case in the determination of critical exponents !), the results above and below $p_{\mathrm{c}}$ are described by a straight line with the same slope $v=1.06 \pm 0.1$.

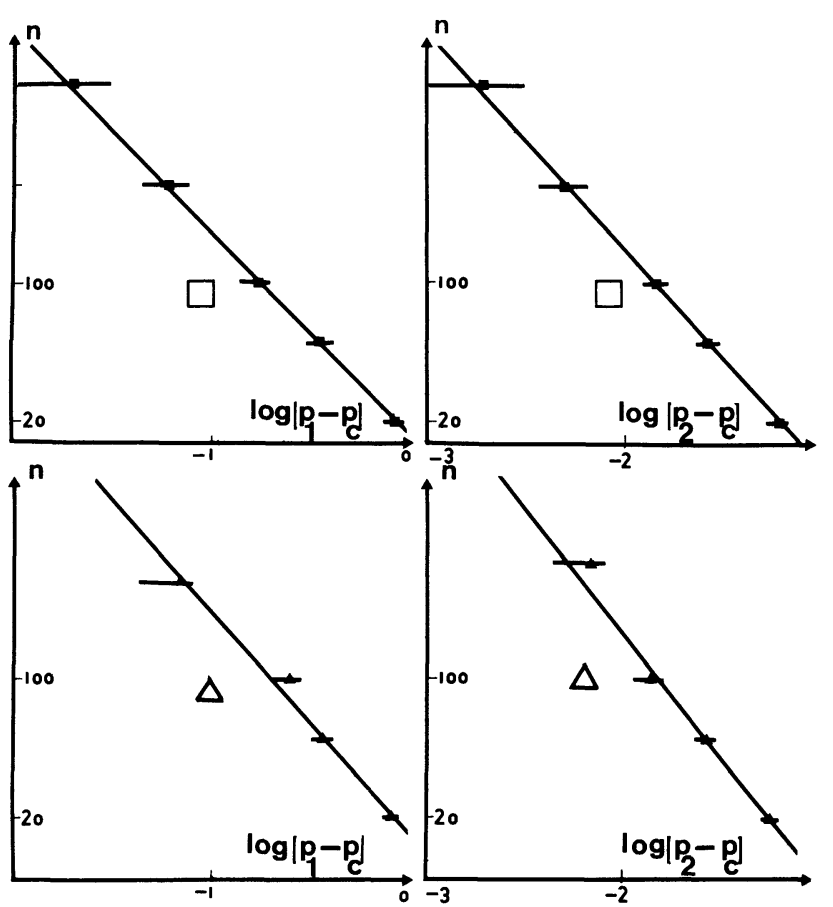

FIG. 3. - Same as figure 2 in log-log units indicating the power divergence of a characteristic length for square networks $(\square)$ and triangular networks $(\triangle)$.

For square lattices, $p_{\mathrm{c}}$ has been adjusted to give the best linear fit; the value $p_{\mathrm{c}}=0.595$ obtained is consistent with the values known for $p_{\mathrm{c}}[1,6]$. The slope is $v=1.1 \pm 0.1$. This insensitivity of the value of $v$ to the type of network points towards a certain 
universality of the meaning of the scaling length in this problem.

Recently the percolation problem has been analyzed in the framework of the renormalization group approach [7] using the Potts model [8]. The value obtained here is not inconsistent with the estimates $v=1.3 \pm 0.3$ given in [6] and also obtained with restricted geometry, and with the better results obtained by Padé's approximants method [9].
It is also possible to obtain from this simulation an estimate of the fraction of elements in the critical cluster. This result together with conduction data obtained on spheroid networks as a function of size will be presented in a forthcoming paper.

The authors wish to thank G. Toulouse for helpful discussions, R. Romanetti and the Centre de calcul de l'Université de Provence for their help in the computation, and C. D. Mitescu for a critical reading.

\section{References}

[1] For a detailed review of percolation and conduction we refer to KirkPatricK, Rev. Mod. Phys. 45 (1973) 574.

[2] LAST and Thouless, Phys. Rev. Lett. 27 (1971).

[3] Watson, B. P. and Leath, P. L., Phys. Rev. 89 (1974) 4893.

[4] Clerc, J., Giraud, G., Roussenq, J., C.R. Hebd. sean. Acad. Sci. 281 (1975) 227.

[5] It is worth pointing out that a non conducting configuration is necessarily conducting for the matching lattice. Conversely.
[6] Harris, A. B., Lubensky, T. C., Holcomb, W. K. and DasGUPTA, C., Phys. Rev. Lett. 35 (1975) 327.

[7] Toulouse, G. et PFEUTY, P., Introduction au groupe de renormalisation (Press. Un. Grenoble) 1975.

[8] Kasteleyn, P. W. and Fortuin, C. M., J. Phys. Soc. Japan suppl. 26 (1969) 11.

[9] For the Padé's approximants method, see Stanley, H. E., Introduction to phase transition and critical phenomena (Oxford University Press) 1971, p. 158. 